\title{
Antifungal Activity of Polyhexamethyleneguanidine Derivatives Introduced into Biodegradable Polymers
}

\author{
Maria Swiontek Brzezinska ${ }^{1}$ - Maciej Walczak ${ }^{1}$ - Aleksandra Burkowska-But ${ }^{1} \cdot$ Marta Chylińska $^{2}$. \\ Agnieszka Kalwasińska ${ }^{1} \cdot$ Joanna Świątczak ${ }^{1}$
}

Published online: 17 May 2019

(c) The Author(s) 2019

\begin{abstract}
Experiments were conducted to investigate the antifungal activities of polyhexamethyleneguanidine (PHMG) derivatives introduced into polylactide (PLA), polyhydroxybutyrate (PHB) and polycaprolactone (PCL) against Aspergillus niger, Penicillium chrysogenum and Candida albicans. All of the PHMG derivatives inhibited the germination of $A$. niger and $P$. chrysogenum. All of the derivatives exerted a much stronger inhibitory effect on the cells of $C$. albicans. PHMG granular polyethylene wax (at the concentration of $1.0 \%$ ) has a fungicidal effect. The reduction in the number of yeast cells capable of growing on the surface composites PLA, PHB and PCL with PHMG granular polyethylene wax for $24 \mathrm{~h}$ was R $>2$. PHMG derivatives introduced into PLA decreased hydrolases activity in A. niger and P. chrysogenum. All of the PHMG derivatives introduced into all investigated polymers inhibited the hydrolases activity in $C$. albicans proportionately to concentration. PHMG granular polyethylene wax at a concentration of $1.0 \%$ most strongly inhibited hydrolases activity in yeast. The composites produced from PLA, PHB, PCL and this PHMG derivatives can be used in many areas to reduce the growth of yeast. The studied composites can potentially be used for the production of biomedical or packaging materials.
\end{abstract}

\section{Graphical Abstract}

PHMG derivates introduced into polymer have slightly biocidal properties against molds and strong against yeast. The composites produced from PLA, PHB, PCL and this PHMG derivatives can be used in the many areas to reduce the growth of yeast. The studied composites can potentially be used for the production of biomedical or packing materials.

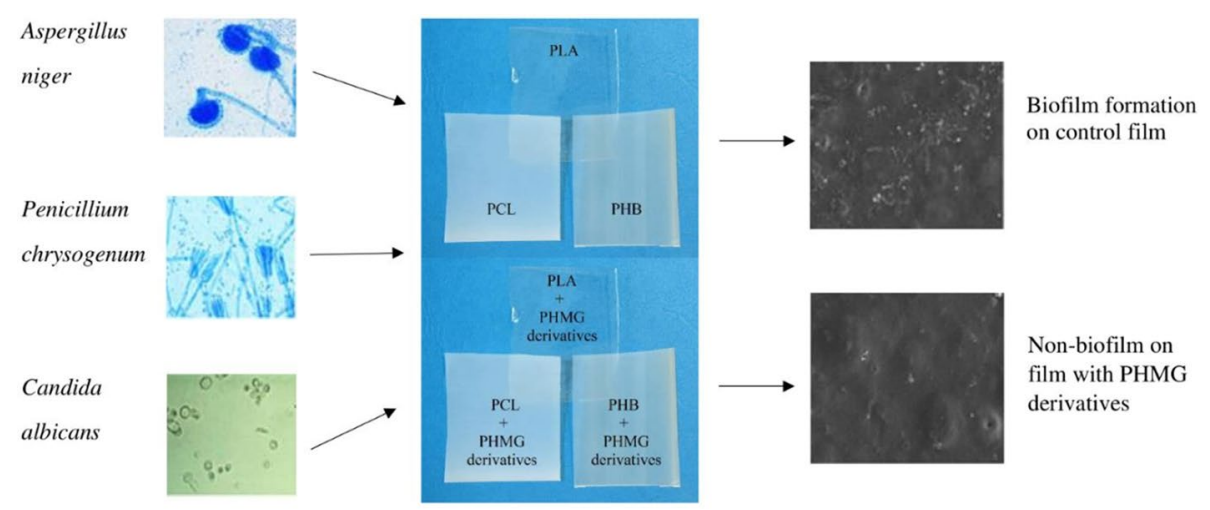

Keywords Biodegradable polymer $\cdot$ PHMG derivatives $\cdot$ Hydrolases

Maria Swiontek Brzezinska

swiontek@umk.pl

Extended author information available on the last page of the article 


\section{Introduction}

For the past few years, intensive research has been carried out in the field of environmentally friendly biodegradable and biocompatible polymers such as polyesters, polyanhydrides, poly(ester amide)s, and biodegradable polyurethanes [1]. Polycaprolactone, polyglycolide, polylactide and polybutylene adipate-co-terephalate find applications in various fields, for example, food packaging [2-4], compost bags, medical sutures, nanoscale or microscale drug delivery vehicles, and temporary scaffolds for tissue regeneration [5-7]. A serious threat to these polymers is the ability to form biofilms. For a few years, the polymer has been modified by introducing different biocidal substances. Introducing antimicrobial substances into polymers by covalent linkages is possible using different methods. According to Jao et al. [8] the antibacterial polymers can be grafted on biodegradable polymers, as shown for grafting of chitosan on polybutyleneadipate-co-terephthalate. Research is being conducted on a number of biocidal substances that potentially can be introduced into polymers. For example, direct contact of $N$-halamine acts as a biocidal on E. coli and Staphylococcus aureus [9]. Polyhexamethyleneguanidine (PHMG) is a biocidal, cationic polymer based guanidine salt, synthesized from hexamethylenediamine and guanidine $\mathrm{HCl}$ [10]. This polymer is stable over a wide range of $\mathrm{pH} 1-10$, non-flammable, and has a high thermal resistance. PHMG is able to eliminate bacteria and some viruses, fungi and unicellular algae. The mechanism of action is that PHMG destabilises the osmotic equilibrium and destructs the cytoplasmic membrane in bacteria or fungi [11]. It was also reported a cooperative binding between guanidine derivatives and DNA, and inhibition the activity of enzyme systems, indicating that antibacterial effect might be also related to other interaction [12, 13]. PHMG and its derivatives are becoming increasingly popular due to its broad range of antibacterial activity and relatively low toxicity. Currently guanidine derivatives with biocidal activity are mainly used as disinfectant in human eye infections and wound care, as water treatmentsand in swimming pools, the disinfection of various solid surfaces, and the impregnation of fabrics [14, 15]. PHMG has been proposed too as a safe and highly effective fungicide and disinfectant in fruits challenged with mould $[11,16]$. PHMG derivatives insoluble in water are used as resin and paint coatings or as additives to plastics such as polycarbonate and polyamide [17]. Research into the introduction of PHMG and its derivatives into polymeric materials such as polycaprolactone, polylactide or polyamide has led to the development of the packaging industry. Polyamide 12 film (PA 12) modified polyhexamethylene guanidine dodecylbenzenesulfonate (PHMG-DBS) almost
Table 1 Extrusion conditions of granulate polymers (data from Institute for Engineering of Polymer Materials and Dyes, Poland)

\begin{tabular}{llll}
\hline Extrusion conditions & Polylactide & $\begin{array}{l}\text { Polycap- } \\
\text { rolac- } \\
\text { tone }\end{array}$ & $\begin{array}{l}\text { Polyhy- } \\
\text { droxybu- } \\
\text { tyrate }\end{array}$ \\
\hline Temperature of the first zone $\left({ }^{\circ} \mathrm{C}\right)$ & 180 & 125 & 140 \\
$\begin{array}{l}\text { Temperature of the second, third } \\
\text { and fourth zone }\left({ }^{\circ} \mathrm{C}\right)\end{array}$ & 185 & 130 & 140 \\
$\begin{array}{l}\text { Head temperature }\left({ }^{\circ} \mathrm{C}\right) \\
\text { Screw speed }\left(\mathrm{min}^{-1}\right)\end{array}$ & 185 & 130 & 150 \\
Cooling & 250 & 250 & 250 \\
Dosing capacity $\left(\mathrm{kg} \mathrm{h}^{-1}\right)$ & Air & Air & Air \\
\hline
\end{tabular}

completely inhibited the growth of moulds [18]. Yeasts, moulds and mycotoxins are a serious threat because they are, for example, a cause of many food poisonings [19]. The introduction of biocidal substances into packaging materials could protect the food against fungal infections. The fungicidal activity of PHMG is shown by Feng et al. [20]. However, it is not known whether PHMG after incorporation into the polymers also has a biocidal effect. So far, studies have been carried out on the bactericidal properties of PHMG derivatives introduced into polymers. Hence, the purpose of our study was to investigate whether PHMG derivatives introduced in biodegradable polymers have fungicidal properties and the effect of the derivatives on extracellular hydrolytic enzymes.

\section{Materials and Methods}

\section{Preparation of Composites}

For the production of the tested composites biodegradable Polylactide polymer type 2002D (NatureWorks $®$, USA) were used with density $\mathrm{d}=1.24 \mathrm{~g} \mathrm{ml}^{-1}$, Poli ( $\varepsilon$-caprolactone) polymer, type CAPA 6800 (Solvay Caprolactones, UK) with density $\mathrm{d}=1.1 \mathrm{~g} \mathrm{ml}^{-1}$ and $\mathrm{t}$ SoGreen ${ }^{\circledR}$-2001a (Tianjin Green BioMaterial Company, China) polymer mixture containing poly (3,4-hydroxybutyrate), density $\mathrm{d}=1.25 \mathrm{~g} \mathrm{~cm}^{-3}$. Extrusion conditions of granulate polymers show Table 1 . The three biocidal PHMG derivatives with organic anions: sulfanilic acid salt, stearate, and granular polyethylene wax were used to study. All composites were from the Institute for Engineering of Polymer Materials and Dyes, Poland. The mixture of polymers and additional ingredients were prepared with the use of a co-rotating twin-screw extruder type BTSK 20 (Bühler, Germany) with the screw diameter of $20 \mathrm{~mm}$ and $\mathrm{L} / \mathrm{D}=40$, equipped with a segmented plasticizing system used to produce granulated composite. Prior to extrusion of the granulate PLA and PHB materials with moisture removed by placing them in a vacuum thermal chamber (Piovan) at $75^{\circ} \mathrm{C}$ and 
$60{ }^{\circ} \mathrm{C}$ respectively for $4 \mathrm{~h}$. Poly ( $\varepsilon$-caprolactone) was extruded directly, because it does not require prior drying under appropriate conditions. The composite was cold-granulated with cooling of the pomace in the air at a temperature of $25 \pm 3{ }^{\circ} \mathrm{C}$. The granulated product was used to produce flat films using a single-screw extruder type PlastiCorder PLV 151 (Brabender, Germany) equipped with a screw with a diameter of $19.5 \mathrm{~mm}$ and $\mathrm{L} / \mathrm{D}=25$ equipped with a flat head width of $170 \mathrm{~mm}$ die with adjustable gap size and cooperating with triple roll calender rolls having a diameter of $110 \mathrm{~mm}$ whose temperature is stabilized by a thermostat. The prepared samples had the following contents of PHMG derivatives: 0.0, 0.2, 0.6, 1.0\% $(w t)$. The following symbols of the composites were used in the tests: PLA/PHB/PCL-A (PLA/PHB/PCL with the PHMG salt of sulfanilic acid), PLA/PHB/PCL-W (PLA/PHB/PCL with PHMG granular polyethylene wax), PLA/PHB/PCL-S (PLA/PHB/PCL with PHMG stearate). Control samples were pure PLA, PHB and PCL without PHMG derivatives. The tested PHMG derivatives are compounds of a copolymer produced by PHMG synthesis of an organic carrier according to Patent No: P.388062, 2009 [21]. The biocidal properties of the organic copolymer have been previously investigated. The biocidal effect of the copolymers (sulfanilic acid, granular polyethylene wax, stearate) introduced into PLA/PHB/PCL in concentration $0.2-1.0 \%$ was not observed. All composites were from the Institute for Engineering of Polymer Materials and Dyes, Poland.

\section{Determination of Blood Compatibility}

The hemolytic activity of PHMG derivatives introduced into the polymers was tested by direct contact methods, according to the modified method Zhou et al. [22]. All derivatives with PHMG concentrations of 0.6 and $1.0 \%$ were selected for the study. For this purpose $200 \mu \mathrm{l}$ anticoagulated sheep blood was added to $10 \mathrm{ml}$ of physiological saline solution containing derivatives PHMG $\left(1 \mathrm{~cm}^{2}\right.$ area). The positive and negative control was prepared by adding $200 \mu \mathrm{l}$ of fresh blood to water and physiological saline, respectively. After one hour incubation at $37{ }^{\circ} \mathrm{C}$ the suspensions were centrifuged $(1000 \mathrm{rpm}$, $10 \mathrm{~min}$ ). The absorbance of the supernatant of each sample was measured by microplate reader Multiscan FC (Thermo Fisher Scientific, Waltham, USA) at $540 \mathrm{~nm}$. The study was prepared in triplicate. Hemolysis rate was calculated using this equation:

Rate of hemolysis $(\%)=($ ODspecimen - ODnegative $) /($ ODpositive - ODnegative $) \times 100$
ATCC10106 were used for the study. The yeasts and moulds were maintained on Malt Extract Agar (Biocorp) medium at $4{ }^{\circ} \mathrm{C}$. The $C$. albicans was subcultured on appropriate medium at $37{ }^{\circ} \mathrm{C}$ and moulds at $26^{\circ} \mathrm{C}$ for $48 \mathrm{~h}$.

\section{Antifungal Activity Assay}

A common method for determining antimicrobial activity is the diffusion method. However, this method could be not used because PHMG derivatives do not diffuse into the medium. Antifungal properties of PLA, PHB and PCL containing PHMG derivatives were determined according to modified standard ISO 22196 [23]. The analysis was performed in triplicate. Control (PLA/PHB/PCL) and test samples (PLA/PHB/PCL-W, PLA/PHB/PCL-S, PLA/PHB/ PCL-A) covered with the fungal suspensions investigated in the research with a specified number of cells or spores $\left(1 \times 10^{5}\right.$ per ml yeast cells or moulds spores with McFarland's standard) were left for a specified time $(0 \mathrm{~h}$-validation of recovery efficiency and $24 \mathrm{~h}$ ). After this time cells were recovered from the surface and suspended in a solution containing neutralizer. Subsequently, the number of cells capable of growth was determined by the inoculation on PDA (moulds) and Sabouraud agar (yeast). The C. albicans was incubated for $48 \mathrm{~h}$ at $37^{\circ} \mathrm{C}$ and moulds were incubated for $48 \mathrm{~h}$ at $26^{\circ} \mathrm{C}$.

Reduction of the number of living and viable cells of tested microorganisms (R) was calculated using the equation:

$\mathrm{R}=\left(\mathrm{U}_{\mathrm{t}}-\mathrm{U}_{0}\right)-\left(\mathrm{W}-\mathrm{U}_{0}\right)$

where Uo is the average of the common logarithm of the number of viable fungi recovered from the control samples (PLA/PHB/PCL) immediately after inoculation (validation of recovery efficiency); $U_{t}$ is the control samples (PLA/PHB/ PCL) after $24 \mathrm{~h}$ (controls of survival in time, without PHMG derivatives); $\mathrm{W}$ is the average of the common logarithm of the number of viable fungi recovered from the test samples (PLA/PHB/PCL-S, PLA/PHB/PCL-W, PLA/PHB/PCL-A) after $24 \mathrm{~h}$.

\section{Scanning Electron Microscopy (SEM) Observation}

PHMG derivatives introduced into polymers showed strong biocidal properties only against $C$. albicans. SEM analysis

\section{Test Microorganisms}

The yeast Candida albicans ATCC10231 and moulds Aspergillus niger ATCC16404 and Penicillium chrysogenum was performed on films of PHB containing 1.0\% PHMG. Fragments $0.5 \times 1.5 \mathrm{~cm}$ of the PHB film (control) and PHBW, PHB-A and PHB-S with 1.0\% PHMG (tested sample) were sterilized with ethyl alcohol and placed in a sterile 
simax bottle with $10 \mathrm{ml}$ YPD medium (composition $\mathrm{g}^{-1}$ ): peptone-20.0, yeast extract-10.0, glucose-20.0). $1 \mathrm{ml}$ suspensions of the yeast with an optical density of 1.0 according to McFarland standards were then transferred to the bottle and incubated at $37{ }^{\circ} \mathrm{C}$ for 7 days. After incubation, the films were washed several times with sterile water and dried. The thus prepared films were subjected to SEM analysis. The SEM images of samples were received using the 1430 VP (2001) scanning electron microscope (LEO Electron Microscopy Ltd, England). In order to achieve images of high quality, the samples were sputter-coated with $\mathrm{Au}-\mathrm{Pd}$ alloy prior to the examination. Images of each sample were taken at $\times 10,000$ magnification.

\section{Determination of Effect of PHMG Derivatives on Hydrolases Activity}

Candida albicans was prepared in flasks containing $50 \mathrm{ml}$ of liquid medium $\left(\mathrm{g} \mathrm{l}^{-1}\right)$ : casein pepton (20), yeast extract (20), glucose (20). Aspergillus niger and P. chrysogenum were cultured in a medium containing $\left(\mathrm{g} \mathrm{l}^{-1}\right): \mathrm{KH}_{2} \mathrm{PO}_{4}$ (0.5) $\mathrm{K}_{2} \mathrm{HPO}_{4}(0.5), \mathrm{MgSO}_{4} \cdot 7 \mathrm{H}_{2} \mathrm{O}(0.3)$, pepton (5), yeast extract (1.5). After $24 \mathrm{~h}$ of incubation at $37^{\circ} \mathrm{C}$ (yeast) and $26{ }^{\circ} \mathrm{C}$ (moulds) the cultures were centrifuged at a speed of $10,000 \mathrm{rpm}$ to separate the cells from the post-culture liquid $\left(+4{ }^{\circ} \mathrm{C}\right)$. The obtained post-culture liquid containing hydrolases were used in further tests. The film $(5 \times 5 \mathrm{~cm})$ with $3 \mathrm{ml}$ of the obtained post-culture liquid was placed on sterile Petri plates. The samples were pre-incubated for $4 \mathrm{~h}$ at $20^{\circ} \mathrm{C}$. The optimum contact time of the film with the post-culture liquid was previously determined. Then the post-culture liquid was collected from the tested film and put into Eppendorf test tubes. The activity of hydrolases after contact with the film was determined with the use of fluorescein diacetate using the Adam and Duncan method [24]. Concentration of the fluorescein released under the influence of hydrolases within $1 \mathrm{~h}$, at $30{ }^{\circ} \mathrm{C}$ was measured using a HITACHI F-2500 spectrofluorimeter at excitation wavelength $480 \mathrm{~nm}$ and emission wavelength $505 \mathrm{~nm}$. The control sample was a film without the biocidal substance. The determination was done in triplicate.

\section{Results and Discussion}

\section{Hemolysis Rate of PHMG Derivatives Introduced into PLA, PHB, PCL}

In this paper, the hemolysis test of derivatives PHMG introduced into the polymer was used. All tested composites were safe and had no hemolytic activity. For all composites the hemolysis value tested were not more than 5.0\% (Table 2). The hemolysis testing is often used as an indicator of the
Table 2 The toxicity of PHMG derivatives incorporated in the polylactide (PLA), polyhydroxybutyrate (PHB) and polycaprolactone (PCL)

\begin{tabular}{|c|c|c|}
\hline Composites & $\begin{array}{l}\text { Concentration } \\
\text { of PHMG (\%) }\end{array}$ & $\begin{array}{l}\text { Rate of } \\
\text { hemolysis } \\
(\%)\end{array}$ \\
\hline $\begin{array}{l}\text { PLA with the PHMG salt of sulfanilic } \\
\text { acid }\end{array}$ & 0.6 & 0 \\
\hline $\begin{array}{l}\text { PLA with the PHMG salt of sulfanilic } \\
\text { acid }\end{array}$ & 1.0 & 0 \\
\hline $\begin{array}{l}\text { PLA with PHMG granular polyethylene } \\
\text { wax }\end{array}$ & 0.6 & 0 \\
\hline $\begin{array}{l}\text { PLA with PHMG granular polyethylene } \\
\text { wax }\end{array}$ & 1.0 & 0.81 \\
\hline PLA with PHMG stearate & 0.6 & 0 \\
\hline PLA with PHMG stearate & 1.0 & 0 \\
\hline $\begin{array}{l}\text { PHB with the PHMG salt of sulfanilic } \\
\text { acid }\end{array}$ & 0.6 & 0 \\
\hline $\begin{array}{l}\text { PHB with the PHMG salt of sulfanilic } \\
\text { acid }\end{array}$ & 1.0 & 1.0 \\
\hline $\begin{array}{l}\text { PHB with PHMG granular polyethylene } \\
\text { wax }\end{array}$ & 0.6 & 0 \\
\hline $\begin{array}{l}\text { PHB with PHMG granular polyethylene } \\
\text { wax }\end{array}$ & 1.0 & 0.38 \\
\hline PHB with PHMG stearate & 0.6 & 0 \\
\hline PHB with PHMG stearate & 1.0 & 0 \\
\hline $\begin{array}{l}\text { PCL with the PHMG salt of sulfanilic } \\
\text { acid }\end{array}$ & 0.6 & 0 \\
\hline $\begin{array}{l}\text { PCL with the PHMG salt of sulfanilic } \\
\text { acid }\end{array}$ & 1.0 & 0.07 \\
\hline $\begin{array}{l}\text { PCL with PHMG granular polyethylene } \\
\text { wax }\end{array}$ & 0.6 & 0 \\
\hline $\begin{array}{l}\text { PCL with PHMG granular polyethylene } \\
\text { wax }\end{array}$ & 1.0 & 0.11 \\
\hline PCL with PHMG stearate & 0.6 & 0.46 \\
\hline PCL with PHMG stearate & 1.0 & 0.41 \\
\hline
\end{tabular}

injuries to the red blood cell membrane and considered to be a simple and reliable measurement for estimating blood biocompatibility of materials. According to ISO document 10 993-5 1992 hemolysis index is regarded as safe when it is less than 5.0\% [22]. Zhang et al. [25] reported excellent biocompatibility of the PHMG-based hydrogels. The low toxicity of PHMG-based polymers during contact exposure show promise not only for surface protection but even for creation of medical materials.

\section{Antifungal Properties of PHMG Derivatives Introduced into PLA, PHB, PCL}

The antifungal properties of all the derivatives were positively correlated ( $\mathrm{R}$ in the range from 0.65 to 0.75 ) to the concentration of PHMG. All of the PHMG derivatives introduced into PLA, PCL and PHB inhibited the germination of 
Fig. 1 Antifungal activity of PHMG introduced into PLA against moulds and yeast. PLA-A (PLA with PHMG salt of sulfanilic acid), PLA-W (PLA with PHMG granular polyethylene wax), PLA-S (PLS/ with PHMG stearate). Values are expressed as mean $\pm \mathrm{SD}$ $(n=3)$

Fig. 2 Antifungal activity of PHMG derivates introduced into PCL against moulds and yeast. PCL-A (PCL with PHMG salt of sulfanilic acid), PCL-W (PCL with PHMG granular polyethylene wax), PCL-S (PCL with PHMG stearate). Values are expressed as mean $\pm \mathrm{SD}$ $(n=3)$

Fig. 3 Antifungal activity of PHMG introduced into PHB against moulds and yeast. PHB-A (PHB with PHMG salt of sulfanilic acid), PHB-W (PHB with PHMG granular polyethylene wax), PHB-S (PHB with PHMG stearate). Values are expressed as mean $\pm \mathrm{SD}$ $(n=3)$
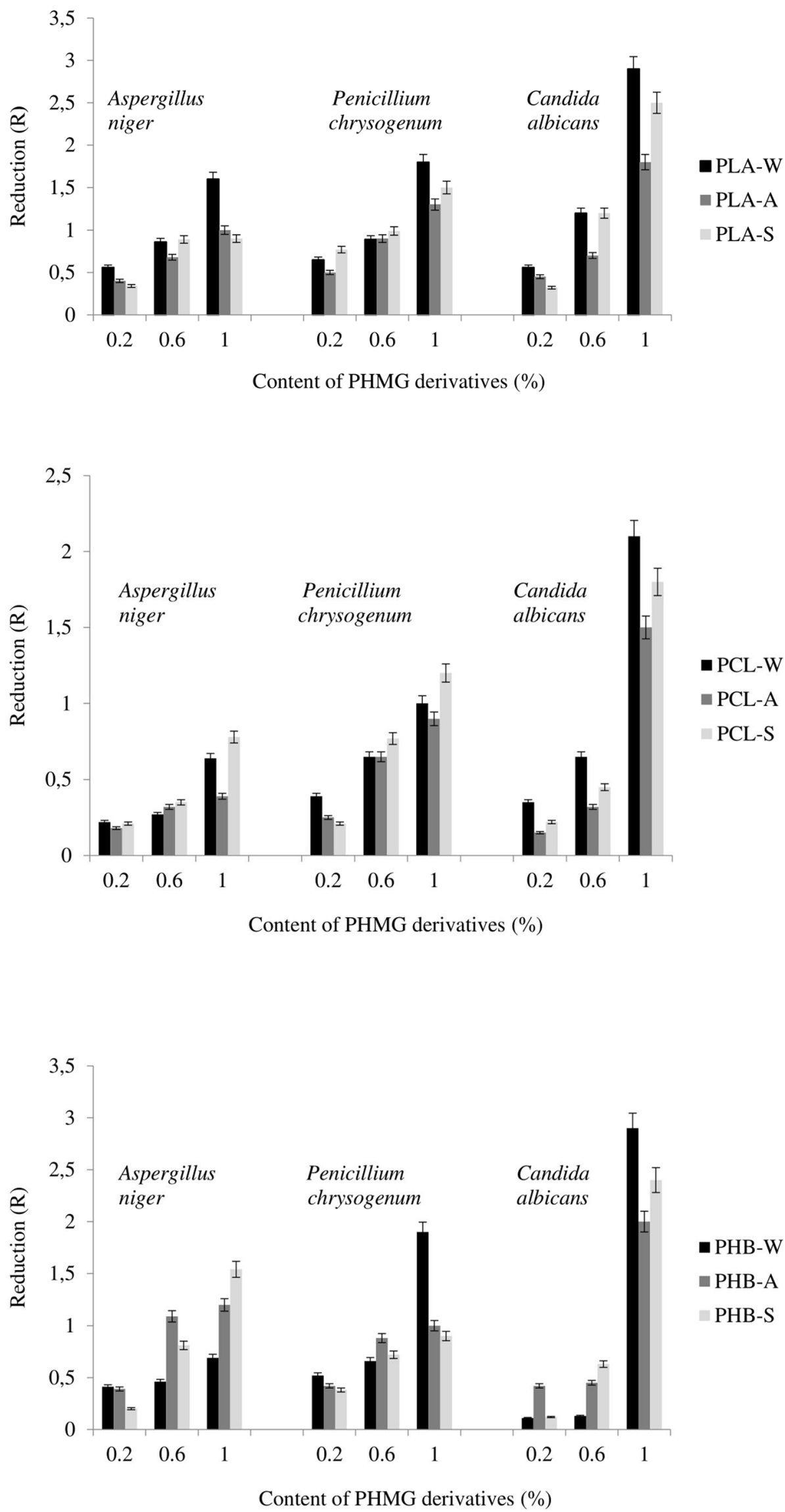

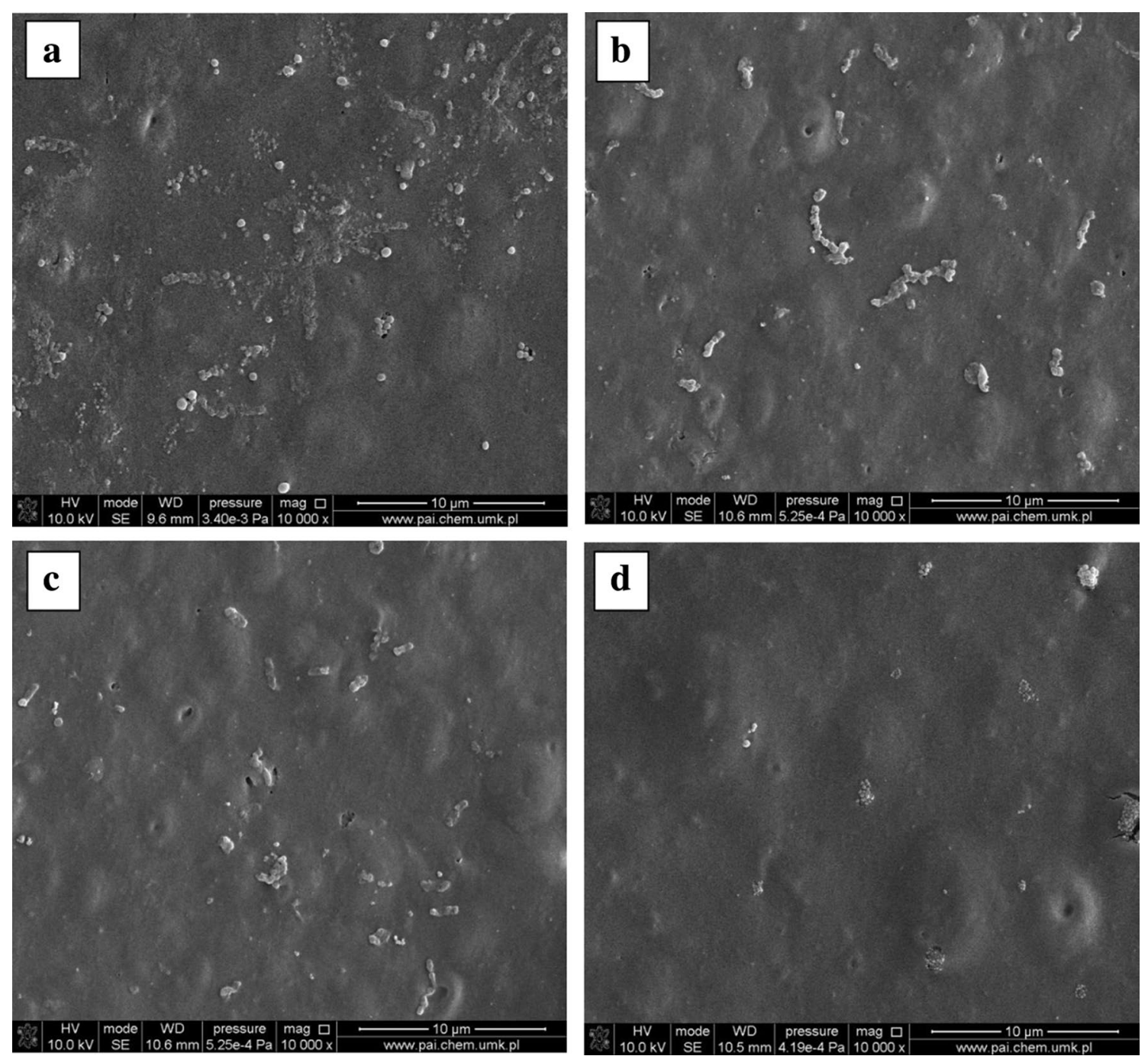

Fig. 4 Scanning electron micrographs of biofilm of $C$. albicans on surface of films containing 1\% PHMG. a PHB without PHMG, b PHB with PHMG salt of sulfanilic acid, $\mathbf{c}$ PHB with PHMG stearate, $\mathbf{d}$ PHB with PHMG granular polyethylene wax

A. niger and $P$. chrysogenum (Figs. 1, 2, 3), but reduction of live cells (R) for both moulds incubated on films containing a 1.0\% PHMG was a smaller than 2. According to standard ISO 2219616 [23], the reduction of the number of cells capable of growth by two orders of magnitude $(R \geq 2)$ is interpreted as a biocidal effect of the investigated composite. All of the derivatives (at the concentration of $1.0 \%$ ) have a much stronger inhibitory effect on the cells of $C$. albicans (Figs. 1, $2,3)$. The reduction of yeast cells capable of growth $(\mathrm{R})$ on the surface composites PLA, PHB and PCL with PHMG granular polyethylene wax (at the concentration of 1.0\%) for $24 \mathrm{~h}$ was $\mathrm{R}>2$. Therefore, the composites PLA-W, PHB-W and PCL-W containing a $1.0 \%$ PHMG can be considered biocidal against yeast.

SEM analysis also shows a significant reduction in the number of yeast cells. On the surface of the PHB film without PHMG was observed a lot of yeast cells. However, on
PHB film containing PHMG salt of sulfanilic acid and stearate granular yeast of cells was less. On surface PHB with polyethylene wax at a concentration of $1.0 \%$ was observed in single yeast cells (Fig. 4).

The study of fungicidal properties of PHMG introduced biodegradable polymers is fragmented. The studies mainly focused on the inhibitory effects of PHMB or PHMG on bacteria growth. PHMB exhibits bacteriostatic properties at low concentrations (typically $1-10 \mathrm{mg}^{-1}$ ) but has bactericidal characteristics at higher concentrations [26, 27]. Feng et al. [20] have demonstrated the fungicidal activity of polyhexamethylene biguanide (PHMB) and polyhexamethylene guanidine (PHMG) against Geotrichum citri-aurantii. According to authors, PHMG and PHMB treatments significantly inhibited arthroconidia germination and mycelial growth of $G$. citri-aurantii in vitro. PHMG and PHMB at $5 \mathrm{mg} \mathrm{l}^{-1}$ inhibited $97.8 \%$ and $95.8 \%$ of the germination 
Fig. 5 Effect of PHMG introduced into PLA on hydrolase moulds and yeast. PLA-A (PLA with PHMG salt of sulfanilic acid), PLA-W (PLA with PHMG granular polyethylene wax), PLA-S (PLA with PHMG stearate). Values are expressed as mean $\pm \mathrm{SD}(n=3)$

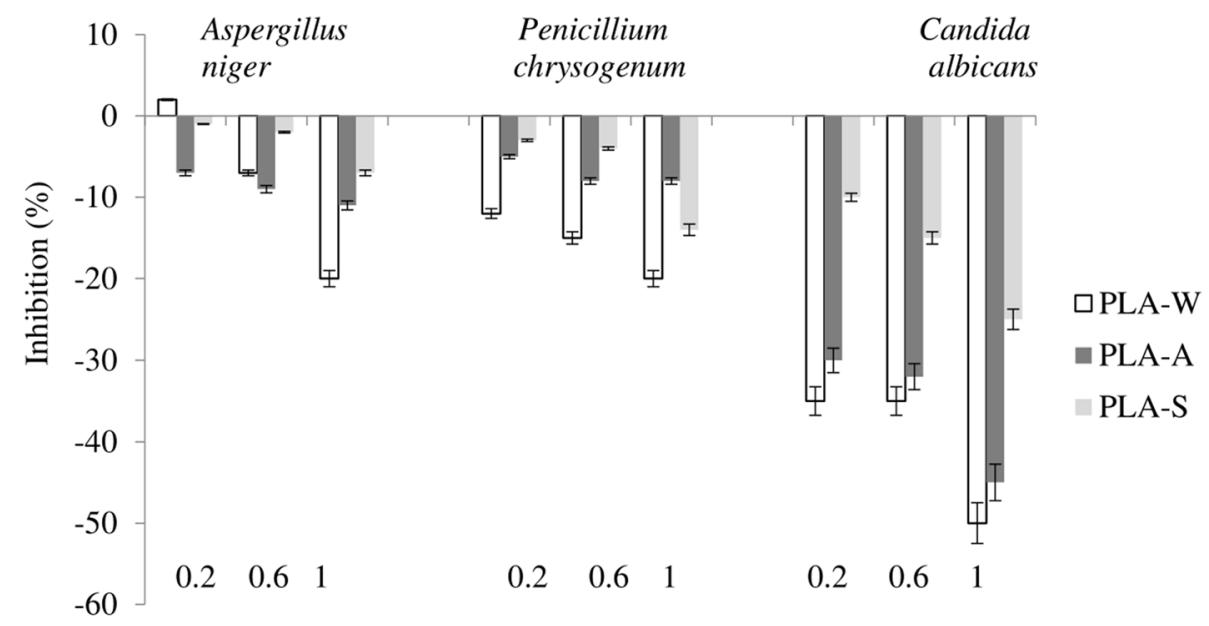

Content of PHMG derivatives (\%) of G. citri-aurantii arthroconidia, respectively. RazzaghiAbyaneh et al. [28] reported that PHMG inhibited fungal growth of Aspergillus parasiticus in a dose-dependent manner, and can inhibit completely the growth of $A$. parasiticus when a concentration of $2 \mathrm{mg}^{-1}$ is used. Choi et al. [29] showed that the antifungal activity of PHMGH was greater than or equal to that of amphotericin B. In particular, PHMGH (1.25 $\mu \mathrm{g} \mathrm{ml}^{-1}$ ) was more potent than amphotericin $\mathrm{B}\left(2.5 \mu \mathrm{g} \mathrm{ml}^{-1}\right)$ against Candida species.

The antimicrobial activity of PHMB could be attributed to its ability to cause phospholipid phase separation and loss of membrane function in bacteria and yeast [26, 30, 31]. Zhou et al. [27] reported that PHMG damaged membrane and intracellular structures of $E$. coli, resulting in subsequent leakage of intracellular components and cellular inactivation. According to Feng et al. [20] PHMG and PHMB markedly damaged hyphal plasma membranes of $G$. citri-aurantii, possibly by a similar mechanism to that of E. coli. Similarly, Schindler and Hauser [32] reported that PHMG diffuses through the cellular membrane and binds to the cytoplasmic membrane forming a complex with the phospholipid molecules of the lipid bilayer, destabilizes the osmotic equilibrium and destroys cytoplasmic membrane, causing leakage of the cell content. According to Choi et al. [29] the antifungal mechanism assay, using C. albicans as a model, suggests that PHMGH exerts its antifungal activity by forming pores in the plasma membrane with the majority of pore size being between 2.3 and $3.3 \mathrm{~nm}$, causing an ion loss.

There is no doubt that PHMG has biocidal properties [10, 11]. However, the strength of its performance may change after modification. The incorporation of PHMG into polymers can reduce the power, therefore a PHMG concentration with a biocidal effect must be established. In addition, the sensitivity of various microorganisms to PHMG is different. Our studies showed inhibition of germination of A. niger and
$P$. chrysogenum, but it was lower than two orders of magnitude $(\mathrm{R}<2)$. Therefore according to standard ISO 2219616 [23] the investigated composite have not a biocidal effect against moulds. On the other hand, our study showed that after incubation of $C$. albicans on PLA, PHB and PCL films containing granular polyethylene wax at a concentration of $1.0 \%$ PHMG for $24 \mathrm{~h}$, there was a reduction of live yeast cells $\mathrm{R}>2$. According to standard ISO 2219616 [23] these composites showed a biocidal effect against yeast. It means that, mould spores can be more resistant to PHMG than yeasts. Walczak et al. [33] determined bactericidal properties of polylactide (PLA) films containing three different PHMG derivatives. According to the authors only PLA-W (at a concentration of at least $0.6 \%$ ) has a bactericidal effect. For E. coli and Staphylococcus aureus strains incubated on PLA films containing PLA-W at a concentration of 0.6 and $1.0 \%$ for $24 \mathrm{~h}$, there was a reduction of live and viable bacterial cells $\mathrm{R} \geq 2$. Kondratyuk et al. [18] tested the fungicidal properties of polyamide foils (PA-12). They were coated with polyhexamethylene guanidine dodecylbenzenesulfonate (PHMG-DBS) at a concentration of 3-10\%. Tests were carried out against test mixtures culture: Aspergillus terreus, A. niger, Penicillium funiculosum, P. ochrochloron and Trichoderma viride. PA-12 films were found to have pronounced antifungal properties when modified with $5 \mathrm{wt} \%$ of polymeric biocide PHMG-DBS. The absence of colonies of fungal test-cultures on the PA-12 film surface was observed under the experimental conditions.

\section{Effect of PHMG Derivatives on Fungal Hydrolase Activity}

PHMG derivatives introduced into PLA decreased hydrolases activity in $A$. niger and $P$. chrysogenum. PLA with the PHMG salt of sulfanilic acid and granular polyethylene wax strongly inhibited activity of $C$. albicans hydrolases, 
Fig. 6 Effect of PHMG introduced into PCL on hydrolase moulds and yeast. PCL-A (PCL with PHMG salt of sulfanilic acid), PCL-W (PCL with PHMG granular polyethylene wax), PCL-S (PCL with PHMG stearate). Values are expressed as mean $\pm \mathrm{SD}(n=3)$

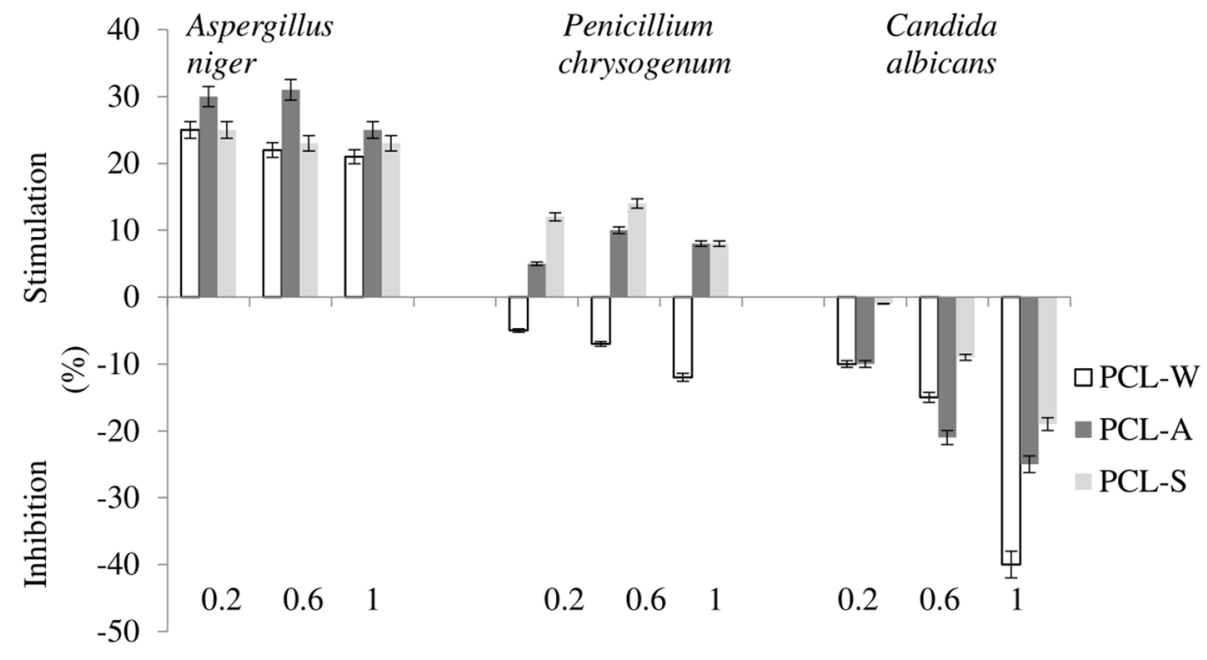

Content of PHMG derivatives (\%)

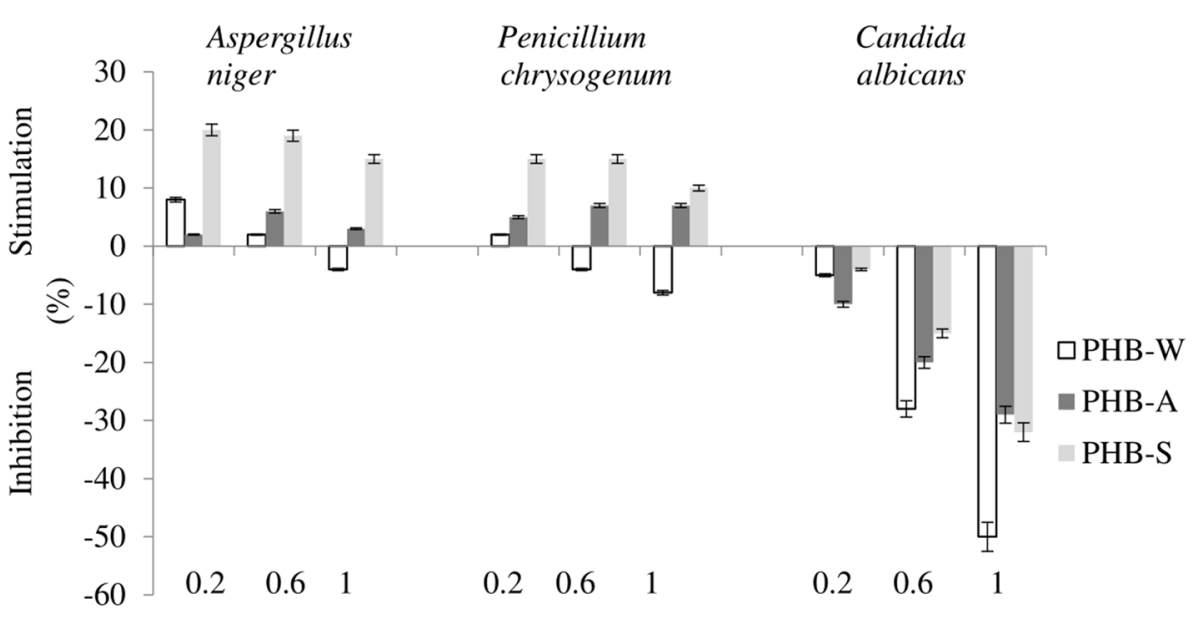

Content of PHMG derivatives (\%)
Fig. 7 Effect of PHMG introduced into PHB on hydrolase moulds and yeast. PHB-A (PHB with PHMG salt of sulfanilic acid), PHB-W (PHB with PHMG granular polyethylene wax), PHB-S (PHB with PHMG stearate). Values are expressed as mean $\pm \mathrm{SD}(n=3)$ proportionately to the concentration (Fig. 5). Some PHMG derivatives introduced into PCL and PHB stimulated hydrolase activity in moulds. However PCL and PHB films with the PHMG granular polyethylene wax at a concentration $1.0 \%$ most strongly inhibited a hydrolases activity in yeast and state ranges from 40 to $52 \%$ depending on the type of film (Figs. 6, 7).

PHMG not only affects the permeability of the cell membrane of microorganisms but it can also inhibit the activity of enzyme systems such as hydrolysis responsible for degradation of polymers. Our research shows that PHMG significantly inhibited only the activity of C. albicans hydrolases. Walczak et al. [13] and Swiontek Brzezinska et al. $[34,35]$ studied the effect of PHMG derivatives introduced into the PLA, PHB and PCL on the activity of the bacterial hydrolases. Their research shows that the tested composites do not have a significant impact on reducing the activity of hydrolases. They only observed inhibition of intercellular dehydrogenase activity. The effect of PHMG enzymatic activity inhibition of fungi is not well known. Undoubtedly, damage to the enzyme system will adversely affect the degradation of polymers in the environment. PLA is a polymer which is totally biodegradable by proteases, mainly serine proteases and esterases. Biodegradation, depending on the conditions under which it is carried out, may be slow or fast. Rapid degradation is conducive to high temperature and humidity [36]. PHB is degraded with esterases. Penicillium funiculosum and Aspergillus fumigatus are capable of producing these enzymes [37, 38]. Similarly, PCL degradation occurs with lipase and esterase [39]. Aspergillus sp. Penicillium sp., some filamentous fungi and yeast are capable of PCL hydrolysis [40]. Our research has shown that PHMG derivatives do not adversely affect the activity 
of fungal hydrolases, so that the degradation of the tested composites in the environment will not be disturbed.

\section{Conclusions}

All of the PHMG derivatives inhibited the germination of $A$. niger and $P$. chrysogenum. All of the PHMG derivatives had a much stronger biocidal effect on the cells of $C$. albicans. All of the PHMG derivatives inhibited the germination of $A$. niger and $P$. chrysogenum. All of the PHMG derivatives had a much stronger biocidal effect on the cells of $C$. albicans. The composites produced from PLA, PHB, PCL and PHMG granular polyethylene wax derivative in concentration $1.0 \%$ can be used in many areas to reduce the growth of yeast (e.g. the production of biomedical or packaging materials). At the same time, PHMG derivatives introduced into biodegradable polymer do not adversely affect the hydrolase in A. niger and $P$. chrysogenum and therefore biodegradation of composites in the environment can proceed correctly.

\section{Compliance with Ethical Standards}

Conflict of interest The authors declare that they have no conflict of interest.

Ethical Approval Research did not involve Human Participants and/ or Animals.

Open Access This article is distributed under the terms of the Creative Commons Attribution 4.0 International License (http://creativeco mmons.org/licenses/by/4.0/), which permits unrestricted use, distribution, and reproduction in any medium, provided you give appropriate credit to the original author(s) and the source, provide a link to the Creative Commons license, and indicate if changes were made.

\section{References}

1. Wang H, Langner M, Agarwal S (2016) Eng Science 56:1146

2. Siracusa V, Rocculi P, Romani S, Rosa MD (2008) Trends Food Sci Technol 19:634

3. Marten E, Müller RJ, Deckwer WD (2005) Polym Degrad Stabil $88: 371$

4. Herrera R, Franco L, Rodriguez-Galán A, Puiggali J (2002) J Polym Sci Part A 40:4141

5. Nair LS, Laurencin CT (2007) Prog Polym Sci 32:762

6. Lendlein A (1999) Med Chem 33:279

7. Vert M (2009) J Mater Sci 20:437

8. Jao WC, Lin CH, Hsieh JY, Yeh YH, Liu CY, Yang MC (2010) Polym Adv Technol 21:543

9. Chylińska M, Kaczmarek H, Burkowska-But A, Walczak M (2015) J Ind Eng Chem 28:124

10. Zhou ZX, Wie DF, Guan Y, Zheng AN, Zhong J (2011) J Mat Sci Eng C 31:1836
11. Olmedo GM, Cerioni L, Sepulveda M, Ramallo J, Rapisarda VA, Volentini SI (2018) Food Microbiol 76:128

12. Allen MJ, White GF, Morby AP (2006) Microbiology 152:989

13. Walczak M, Richert A, Burkowska-But A (2014) J Ind Microbiol Biotechnol 41:1719

14. Das S, Sahu SK, Sharma S, Nayak SS, Kar S (2010) Am J Ophthalmol 150:110

15. Gendaszewska D, Szuster L, Wyrębska Ł, Piotrowska M (2018) Fibres Text East Eur 26(2):73

16. Koffi-Nevry R, Manizan AL, Tano K, Bi YCY, Oulé MK, Koussemon M (2011) Afr J Microbiol Res 5:4162

17. Vointseva II, Efimov KM, Martynenko SV, Skorokhodova ON (2006) Russ Pat RU 2(309):172

18. Kondratyuk TO, Bardeau JF, Sobko VM, Tarasyuk OP, Makhno SM, Sheludko EV, Kyseloov YV, Rogalsky SP (2014) International conference "Modern Problems of Surface Chemistry" Kijow

19. Yotis W (2004) Medical mycology, microbiology and immunology. McGraw-Hill Companies, New York

20. Feng L, Wu F, Li J, Jiang Y, Duan X (2011) Posth Biol Technol $6: 160$

21. Królikowski B, Szuster L, Wyrębska Ł (2009) Polish Patent Aplication Number P388062

22. Zhou HY, Zhang YP, Zhang WF, Chen XG (2011) Carbohydr Polym 83:1643

23. ISO 22196 (2011) Plastics measurement of antibacterial activity on plastics surfaces

24. Adam G, Duncan H (2001) Soil Biol Biochem 33:943

25. Zhang C, Ying Z, Luo Q, Du H, Wang Y, Zhang K, Yan S, Li X, Shen Z, Zhu W (2017) J Polym Sci A 55:2027

26. Allen MJ, White GF, Morby AP (2006) Microbiology 152:989

27. Zhou ZX, Wei DF, Guan Y, Zheng AN, Zhong JJ (2010) J Appl Microbiol 108:898

28. Razzaghi-Abyaneh M, Shams-Ghahfarokhi M, Kawachi M, Eslamifa A, Schmidt OJ, Schmidt A, Allameh A, Yoshinari T (2006) Toxicon 48:1075

29. Choi H, Kim KJ, Lee DG (2007) Fungal Biology 121:53

30. Broxton P, Woodcock PM, Heatley F, Gilbert P (1984) J Appl Bacteriol 57:115

31. Elsztein C, de Menezes JA, de Morais MA (2008) J Ind Microbiol Biotechnol 35:967

32. Schindler WD, Hauser PJ (2004) Textile institute, manchester chemical finishing of textiles. CRC Press, Boca Raton. https:// www.booksgooglecomar/books?id=4jkUpC1OtuwC

33. Walczak M, Swiontek Brzezinska M, Richert A, Kalwasińska A (2015) Int Biodeter Biodegr 98:1

34. Swiontek Brzezinska M, Walczak M, Richert A, Kalwasinska A, Pejchalova M (2016) Appl Biochem Microbiol 52:298

35. Swiontek Brzezinska M, Walczak M, Jankiewicz U, Pejchalova M (2017) J Polym Environ. https://doi.org/10.1007/s1092 4-017-0974-9

36. Nowak B, Pajak J (2010) Arch Waste Manag Environ Protect 12:1

37. Tokiwa Y, Calabia BP (2004) Biotech Lett 26:1181

38. Lee T, Grinshpun SA, Martuzevicius D, Adhikari A, Crawford MC, Reponen T (2006) Atm Environ 40:2902

39. Jayasekara R, Harding I, Bowater I, Longergan G (2005) J Polym Environ 13:231

40. Leja K, Lewandowicz G (2010) Pol J Environ Stud 19:255

Publisher's Note Springer Nature remains neutral with regard to jurisdictional claims in published maps and institutional affiliations. 


\section{Affiliations}

Maria Swiontek Brzezinska ${ }^{1}$ - Maciej Walczak ${ }^{1} \cdot$ Aleksandra Burkowska-But $^{1} \cdot$ Marta Chylińska $^{2}$. Agnieszka Kalwasińska ${ }^{1}$ Joanna Świątczak ${ }^{1}$

1 Department of Environmental Microbiology and Biotechnology, Faculty Biology and Environmental Protection, Nicolaus Copernicus University in Torun, Lwowska 1, 87-100 Torun, Poland
Faculty of Chemistry, Department of Chemistry and Photochemistry of Polymers, Nicolaus Copernicus University in Torun, Gagarina 7, 87-100 Torun, Poland 